\title{
Stimulating pre-service teachers' content and pedagogical content knowledge on rational numbers
}

\begin{abstract}
The transition from natural to rational numbers is difficult for most elementary school children. A major cause for these difficulties is assumed to be the "conceptual change" they need to undergo in order to see that several natural number properties do not apply to rational numbers. To appropriately handle pupils' difficulties, teachers need well-developed content knowledge (CK) and pedagogical content knowledge (PCK). In the present study, a lesson series to promote pre-service teachers' (PSTs) rational number CK and PCK was developed according to design principles to foster conceptual change. This lesson series was evaluated based on a comparison of the CK and PCK growth of PSTs in the intervention group ( $n=138)$ with the knowledge growth of PSTs in an alternative teacher training course (control group; $n=135$ ). Intervention group PSTs significantly outperformed control group PSTs on CK and PCK, indicating that the intervention was effective in stimulating PSTs' knowledge on rational numbers. Methodological, theoretical as well as practical implications of the present study are discussed.
\end{abstract}

Keywords: content knowledge; pedagogical content knowledge; elementary school mathematics; rational numbers

\section{Introduction}

Research has shown elementary school pupils' difficulties in understanding and operating with rational numbers ${ }^{1}$ (e.g., Cramer, Post, \& delMas, 2002; Lamon, 2005; Moss \& Case, 1999; Ni \& Zhou, 2005). A main cause of pupils' difficulties with rational numbers is assumed to be the discrepancy between pupils' deeply rooted prior knowledge about natural numbers which they apply to rational numbers, while the rational number system differs in several ways from the natural number system (Vamvakoussi, Van Dooren, \& Verschaffel, 2012). For instance, many pupils incorrectly assume that $\frac{2}{5}+\frac{3}{4}=\frac{5}{9}$, because $2+3$ equals 5 , and $5+4$ equals 9. Using the "framework theory of conceptual change" (Vamvakoussi, Vosniadou, \& Van Dooren, 2013), the learning of rational numbers is claimed to require a thorough restructuring of pupils' prior knowledge about natural numbers. Realizing this conceptual change in pupils requires from teachers appropriate professional knowledge, more particularly content knowledge (CK, i.e., knowledge about rational numbers) as well as pedagogical content knowledge (PCK, i.e., knowledge about how to teach rational numbers, taking into account pupils' difficulties) (Shulman, 1986). However, there is ample research evidence that preservice teachers (PSTs) have gaps in their CK and PCK on rational numbers (e.g., Ball, 1990; Depaepe et al., 2015; Newton, 2008; Tirosh, 2000; Turnuklu \& Yesildere, 2007). The present study focuses on the way in which PSTs' CK and PCK of rational numbers can be improved in the context of a mathematics methods course in teacher education, combining elements from a design-based research approach (Gravemeijer \& Cobb, 2006; Swalm, 2014) and a more traditional teaching experiment approach (Hattie, Biggs, \& Purdie, 1996). Mathematics education researchers and mathematics teacher trainers co-developed a lesson series on learning to teach rational numbers, informed by instructional design principles that were specifically aimed at promoting

\footnotetext{
${ }^{1}$ A rational number is a number that can be expressed by a fraction $\frac{a}{b}$ in which $a$ and $b$ are whole numbers (with $b$ different from
} $0)$. 
conceptual change. Since learning environments based on design principles to promote conceptual change have proven to be successful in learning in science (Vosniadou et al., 2001), and more recently also in mathematics (Lem, Onghena, Verschaffel, \& Van Dooren, 2017; Vamvakoussi, 2017; Vamvakoussi \& Vosniadou, 2012), in the present study these design principles form the basis of a learning environment to foster PSTs' CK and PCK on rational numbers. To investigate whether the intended change in PSTs' CK and PCK was not merely due to developmental growth in PSTs' professional knowledge we compared the results of the designed lesson series (i.e., the intervention group) with the professional knowledge growth of PSTs in an alternative teacher training course for learning to teach rational numbers (i.e., the control group).

In what follows, the theoretical background gives an overview of elementary school pupils' difficulties with rational numbers, its sources, and the existing research evidence on PSTs' CK and PCK on rational numbers. Next, we present the research methods, including the lesson series and the main design principles that underlie it, followed by the main findings. In the conclusion we sum up the key findings and discuss their theoretical and practical implications.

\section{Theoretical background}

\section{Elementary school pupils' difficulties with rational numbers}

Many elementary school pupils experience difficulties when learning rational numbers (e.g., Cramer et al., 2002; Lamon, 2005; Moss \& Case, 1999; Ni \& Zhou, 2005). These difficulties include, among others, pupils' incorrect understanding of interrelated subconstructs of rational numbers (part-whole, ratio, operator, quotient, and measure) and the relation between different representations of rational numbers (fractions, decimal numbers, and percentages) (Charalambous \& Pitta-Pantazi, 2007). Meanwhile, it is generally acknowledged that rational numbers play an important role in everyday life and that a profound rational number understanding is crucial for learning more advanced mathematics, such as algebra and probability (e.g., Behr et al.,1983; Siegler et al., 2012).

According to the "framework theory of conceptual change" (Vamvakoussi et al., 2013), a source of pupils' difficulties with rational numbers is the discrepancy between pupils' deeply rooted prior knowledge about natural numbers and certain features of the rational number system (Vamvakoussi et al., 2012). Young children develop a personal implicit theory on numbers and how to operate with them, which is heavily based on their prior experiences with natural numbers. This theory assists reasoning in mathematics-related activities, such as ranking numbers or doing arithmetic operations with them. Later, pupils also rely on this implicit theory to give meaning to rational numbers (Ni \& Zhou, 2005). While this prior knowledge might foster new learning in case of similarities between the natural and rational number system (e.g., $\frac{3}{4}>\frac{1}{4}$, since $3>1$ ), it also might hinder new learning when it is inconsistent with properties of the rational number system (e.g., incorrectly assuming that $\frac{14}{57}>\frac{1}{3}$ since $14>1$ and 57 > 3) (Vosniadou \& Verschaffel, 2004). This phenomenon is often referred to as "natural number bias" or "whole number bias". In fact, in cases of inconsistencies between the natural and rational number system, a restructuring of pupils' prior 
knowledge is needed (which in Piagetian terms would be referred to as accommodation, Piaget, 1971). The conceptual change literature suggests that this restructuring might be promoted by (a) systematically and explicitly addressing similarities and differences between natural and rational number thinking, (b) fostering metaconceptual awareness of existing (mis)conceptions on rational numbers, and (c) providing meaningful experiences that reveal why initial conceptions are limited for working with rational numbers and the new conceptions are more intelligible, plausible, and fruitful (Vosniadou et al., 2001).

\section{PSTs' content and pedagogical content knowledge on rational numbers}

Implementing fruitful instructional practices that promote pupils' conceptual change requires appropriate teacher knowledge. In particular, teachers' CK and PCK are important predictors of instructional quality (Baumert et al., 2010; Blömeke et al., 2008; Kunter et al., 2013). Teachers' CK refers to the amount and the organization of their knowledge of the subject matter and PCK entails knowledge of the subject matter for the purpose of teaching, including knowledge of learners' misconceptions and of instructional strategies and representations (Shulman, 1986). Despite the importance of teachers' professional knowledge, there is ample evidence that PSTs (as well as in-service teachers, see, e.g., Khashan, 2014) lack CK and PCK on rational numbers. Given the research evidence on the impact of teachers' professional knowledge on their instructional quality (see, e.g., Baumert et al., 2010; Kunter et al., 2013) this lack of CK and PCK might hamper pupils' opportunities to learn in rational number classrooms. Without the intention to give a complete overview of the research literature, three studies reflecting PSTs' gaps in rational number CK and PCK are summarized.

First, Ball (1990) concluded that PSTs' CK ${ }^{2}$ was narrow, based on questionnaire data and additional interviews regarding division of fractions of elementary and secondary school PSTs at the beginning of formal teacher education. Although, in general, PSTs were able to solve a fraction division task, they had difficulties in understanding the meaning of the algorithm for division of fractions. Regarding PCK, very few secondary and none of the elementary school PSTs were able to generate an appropriate representation for a division of fraction task during the interviews.

Second, Turnuklu and Yesildere (2007) investigated the PCK of elementary school PSTs in their final year of teacher education. Besides some gaps in their CK, PSTs had difficulties in determining pupils' misconceptions about fractions and decimal numbers and their reported instructional approach to overcome these misconceptions was more procedural (i.e., explaining procedures or rules to pupils) than conceptual (i.e., developing insight in the mathematics relations in the task).

${ }^{2}$ Ball (1990) does not refer to the separate constructs CK and PCK, but only uses a single notion "subject matter knowledge for teaching" (in later publications labelled as "mathematical knowledge for teaching" or "content knowledge for teaching mathematics”, e.g., Ball, Thames, \& Phelps, 2008) comprising content knowledge and pedagogical content knowledge. 
Third, Depaepe et al. (2015) investigated the level of elementary and secondary school PSTs' CK and PCK on rational numbers at the end of the first year of a 3-year teacher training program. They administered a validated paper-and-pencil test including CK and PCK items on the concept of and operations with fractions and decimal numbers. Especially elementary school PSTs did not master the necessary CK to teach rational numbers (e.g., incorrectly believing that that $0.9 \div 0.3=0.3$ ). Moreover, elementary and secondary school PSTs' PCK was narrow, both in terms of knowledge of learners' misconceptions and knowledge of instructional strategies and representations.

Given PSTs' gaps in rational number CK and PCK, and the importance of profound CK and PCK for high-quality instruction and learners' learning gains, it is important to investigate the way in which this knowledge can be improved.

\section{Stimulating PST' rational number content and pedagogical content knowledge}

An important source for PSTs' CK and PCK development are theoretical courses in teacher education (Grossman, 1989; Lim-Teo et al., 2007). On the one hand, ascertaining studies have revealed that the content of CK and PCK courses in teacher education might impact PSTs' CK and PCK development (e.g., Evens et al., 2017; Qian \& Youngs, 2016). On the other hand, intervention studies that investigate how PSTs' CK and PCK in the domain of rational numbers can be improved through teacher education remain scarce. There are a few exceptions in which PSTs' development of rational number knowledge is investigated (Newton, 2008; Tirosh, 2000; Whitacre \& Nickerson, 2016).

Newton (2008) interrogated PSTs' CK before and after being enrolled in a semester course that explicitly addressed the link between conceptual and procedural knowledge of fractions. The pretest data indicated weaknesses in PSTs' CK of fractions: PSTs' knowledge of basic concepts was often incorrect, algorithms were regularly misapplied, and transfer and flexibility in solving fraction problems barely occurred. The course resulted in significantly better PST performance on computations with fractions, conceptual knowledge regarding fractions, and fraction word problems. However, PSTs' flexibility in solving fraction problems and transfer of knowledge to novel situations remained low.

Tirosh (2000) investigated the impact of a mathematics methods course in the second year of a 4-year teacher education program on PSTs' CK and PCK on division of fractions. A year-long mathematics methods course was designed to develop PSTs' CK and PCK of rational numbers, taking into account relevant research on pupils' and PSTs' conceptions. The CK focused on rational number concepts and structures. PCK included knowledge of learners' conceptions and misconceptions, sources of these misconceptions, and a repertoire of possible instructional strategies for helping learners to overcome these misconceptions. Tirosh noticed that before the methods course most PSTs correctly solved the CK items but were unable to explain the procedure they used to solve the item. Moreover, they were mostly unaware of pupils' difficulties with rational numbers, with the exception of merely procedural errors, such as algorithmically based mistakes for division of fractions. After the methods course, PSTs made improvements in their CK and PCK. 
More recently, Whitacre and Nickerson (2016) conducted a teaching experiment in which PSTs in their first year of teacher training were interviewed before and after instruction on fraction comparison. The intervention included fraction comparison tasks which were deliberately selected to promote a flexible use of not only standard but also nonstandard strategies to compare different fractions. Standard strategies involved converting fractions to a common denominator or decimal, or interpreting fractions in terms of parts of a whole. Non-standard strategies included referring fractions to the proximity of a benchmark (e.g., one half) or residuals (e.g., distance from 1), or attending to the numerator-to-denominator ratios. The design experiment yielded positive results in terms of PSTs' CK development. More particularly, PSTs used more valid strategies to compare fractions, and became more flexible in comparing fractions, relying on nonstandard and more sophisticated strategies.

\section{The present study}

Given the importance of teachers' deep-level rational number CK and PCK, and the evidence that PSTs have gaps in their CK and PCK on rational numbers, the present study investigates if PSTs' CK and PCK can be stimulated through a lesson series that incorporates several instructional design principles that are brought forward in the literature on the framework theory of conceptual change. These principles have shown to be efficient for fostering learners' science knowledge (Vosniadou et al., 2001) and mathematical knowledge (Lem et al., 2017; Vamvakoussi, 2017; Vamvakoussi \& Vosniadou, 2012). In the present study design principles to promote conceptual change provide the basis for designing a learning environment to promote PSTs' CK and PCK on rational numbers ${ }^{3}$. More particularly, the lesson series (a) systematically and explicitly addresses similarities and differences between natural and rational number reasoning, (b) fosters metaconceptual awareness of existing (mis)conceptions on rational numbers, and (c) provides meaningful experiences that reveal why initial conceptions are limited for working with rational numbers and why new conceptions are more intelligible, plausible, and fruitful. These design principles acted as a framework for designing our instructional materials as well as for the way in which these materials should be implemented by the PSTs' teacher trainers. In line with the design-based research approach to interventional research (Gravemeijer \& Cobb, 2006; Swalm, 2014), the lesson series was co-designed by the researchers and three mathematics teacher trainers and it was implemented in the three teacher training institutes for primary school teachers in Flanders of these three mathematics teacher trainers. To investigate whether the change in PSTs' CK and PCK is not merely due to developmental growth in PSTs' knowledge, we compare, in line with an intervention research approach (Hattie et al., 1996) the results of the designed lesson series with the professional knowledge growth of PSTs of the same institutions enrolled in an alternative teacher training course for learning to teach rational numbers. As such, we tried to combine the strengths of the design-based research approach (e.g.,

\footnotetext{
${ }^{3}$ The complete set of materials of the intervention study is published in a practically oriented textbook (Van Roy, Hawrijk,
} Vermeersch, Palmaerts, \& Depaepe, 2014). 
interdisciplinary teamwork among researchers and practitioners, starting from some guiding principles for designing a hypothetical teaching/learning trajectory, and acting out the designed instruction in real educational settings) with those of a more classical teaching experiment approach (e.g., use of pre- and posttest and of a comparable control group, allowing for systematic evaluation of the effectiveness of the intervention).

\section{Method}

\section{Sample}

Participants were PSTs from three teacher training institutes in Flanders (Belgium). In Flanders, elementary school teachers are trained as general teachers; the curriculum consists of general pedagogy courses, integrated courses of CK and PCK training in all kinds of subjects (e.g., mathematics, language, second language, music), and internships in elementary schools. After three years of training, PSTs receive a professional bachelor-degree for teaching in elementary school (grades 1-6). There is no induction period; teachers immediately take full responsibility as an in-service teacher. Consequently, pre-service teacher training has a high responsibility in developing PSTs' necessary professional knowledge to become an elementary school teacher.

Data of the control group were collected in the same teacher training institutes where the intervention took place, but in the cohort preceding the one that took part in the actual intervention. The PSTs from the control group $(n=138)$ were enrolled in a regular lesson series on teaching rational numbers. PSTs were in their first (one teacher training institute) and second (two teacher training institutes) year of teacher training. The PSTs in the intervention group $(n=135)$ followed the newly developed lesson series in the same phase of their teacher training and spent the same amount of time on the lesson series.

We interrogated participants on the background variables gender and age and no significant differences were observed between the control and intervention group. The percentage of female PSTs was $88.55 \%$ in the control group and $86.41 \%$ in the intervention group; the mean age was respectively 20.51 and 20.65 .

\section{Context of the study}

In Flanders, teacher training for elementary school teachers consists of three years and is organized in professional rather than university institutes. The objective of teacher trainers is to teach PSTs' CK and PCK and to supervise PSTs during their internships. Teacher trainers have a university Master degree, but typically no PhD. Conducting educational research is traditionally not considered as a task for these teacher training institutes, but is for universities. Consequently, "teaching and research in Flemish teacher education have been historically and institutionally separated and conducted by different people with 
different backgrounds and expertise" (Vanassche \& Kelchtermans, 2016, p. 20). As a result, none of the three mathematics teacher trainers involved in our study had been active as a researcher before. Furthermore, and related to the previous aspect, the connection between research and education in regular teacher training courses is rather loose (Verburgh, Schouteden, \& Elen, 2013), implying that in the control group the lesson series was not deliberately and systematically designed according to recent insights from conceptual change research regarding pupils' difficulties with rational numbers and how to prevent or remedy them. More detailed information with respect to the lesson series on learning to teach rational numbers in the intervention and control group is provided in the next section.

\section{The control and intervention lesson series on teaching rational numbers}

All PSTs participated in a lesson series on teaching rational numbers; the main similarities and differences between the control and intervention lesson series are summarized in Table 1.

\section{[Table 1 near here]}

\section{Similarities}

In the intervention and control group the lesson series lasted about $12 \mathrm{~h}(6 \times 2 \mathrm{~h}$, spread over one semester) and was taught by the regular mathematics teacher trainer. The main focus was on PCK, although it also comprised CK. The CK involved in both groups related to basic concepts of rational numbers (e.g., fraction as part-whole, ratio, operator, quotient, and measure; equivalence of fractions; distinct representations of rational numbers; magnitude comparison) as well as procedures (i.e., addition, subtraction, multiplication, and division) to operate with rational numbers. The PCK in both groups involved (1) the place of rational numbers in the elementary curriculum (when is which topic taught), (2) enactive, iconic, and symbolic representations of rational numbers, and (3) topics that elementary pupils find difficult when learning rational numbers - although in the intervention group (2) and (3) were more elaborated based on research-informed evidence. Underlying the lesson series in the intervention and control group was a similar general view on how elementary school mathematics should be learnt and taught, which can be described as a rather eclectic but at the same time quite balanced combination of ideas from mechanistic, structuralistic and realistic approaches to elementary school mathematics (De Bock, Janssens, \& Deprez, 2016; De Bock, Van Dooren, \& Verschaffel, 2016). For instance, the control and intervention lesson series emphasize that in the learning of rational numbers issues of memorization of basic rational number facts and the automatization of computation rules with rational numbers are an important characteristic of highquality instruction for children. Furthermore, as reflected by Figure 1, both the control and intervention lesson series address students' difficulties in acquiring a good conceptual understanding of rational numbers. To effectively deal with these difficulties, both lesson series encourage PSTs to apply a specific and well-designed pedagogical approach for rational numbers. Concretely, 
the application of the CSA (concrete, schematic, abstract) principle, that is, starting from working with concrete (i.e., enactive) via schematic (i.e., iconic) to abstract (i.e., symbolic) notations, is explicitly addressed in both lesson series.

\section{[Figure 1 near here]}

\section{Differences}

The lesson series of the control and intervention group significantly differed on several aspects. First, the intervention lesson series was co-developed by five researchers in mathematics education and the three mathematics teacher trainers, whereas the control lesson series was only developed by the mathematics teacher trainer.

Second, the development of the intervention lesson series was, on the one hand, based on an in-depth analysis of the best practices in the three teacher training institutes. On the other hand, the development process was informed by a thorough literature review on learning and teaching rational numbers, with a special focus on pupils' and PSTs' conceptions and misconceptions of rational numbers and instructional strategies to overcome these misconceptions. In the control group, only very few pitfalls when learning fractions were mentioned and this was done in very broad, and often procedural terms. The intervention lesson series, in contrast, addressed a diversity of pupils' learning difficulties and the sources from which these difficulties originate. For instance, both in the control and intervention lesson series a reference is made to pupils' difficulties with the addition of fractions.

However, as reflected in Figure 2, different from the control group the intervention group explicitly refers to the source of pupils' difficulties in terms of conceptual change theory, that is, the discrepancy between pupils' experience of adding natural numbers and the limitations of their experience when dealing with rational numbers.

\section{[Figure 2 near here]}

Furthermore, in the intervention group a broader variety of mathematical representations to teach rational numbers was addressed compared to the control group.

Third, the intervention lesson series was, contrary to the control group, based on design principles to promote conceptual change. More particularly, throughout the intervention lesson series differences and similarities between natural and rational number reasoning were highlighted (e.g., natural numbers are discrete and rational numbers are dense on the number line, multiplying natural numbers always makes larger whereas multiplying rational numbers can make smaller). Moreover, metaconceptual awareness was aimed at by, among others, stimulating PSTs to discuss pupils' fictitious answers (e.g., represented by printed solutions [see Figure 2] or concept cartoons [see Figure 3]) with their peers and making their conceptions explicit. The 
discussed tasks were deliberately chosen to elicit meaningful experiences for PSTs to show the limitations of their initial conceptions and foster a change of these incorrect conceptions (Vosniadou et al., 2001).

Fourth, concept cartoons and video vignettes were discussed (in small groups of PSTs) in the intervention group to realize design principles to promote conceptual change. Concept cartoons provided PSTs with knowledge of possible learners' misconceptions and simultaneously stimulated metaconceptual awareness, especially if PSTs' own conceptions on rational numbers are inadequate. Previous research has shown that concept cartoons are generally positively valued by learners and helpful to think about their own and other conceptualizations regarding a particular idea (Akamca, Ellez, \& Hamurcu, 2009; Keogh \& Naylor, 1999). Figure 3 illustrates a concept cartoon, in which the teacher asks the pupils to give a fraction smaller than $\frac{5}{15}$.

\section{[Figure 3 near here]}

In Figure 3, one pupil provides a correct answer, i.e. $\frac{1}{4}$, whereas the other pupils hold alternative incorrect conceptualizations. The pupils may have answered $\frac{1}{3}$ or $\frac{1}{2}$ because they incorrectly believe that fractions with smaller numerators/denominators are smaller than those with larger numerators/denominators (Hartnett \& Gelman, 1998). Alternatively, the pupil who answered $\frac{1}{3}$ may also have simplified the fraction, which is sometimes confused with "making a fraction smaller" (Beckmann, 2005; Sheffield \& Cruikshank, 2000). Besides concept cartoons, PSTs in the intervention group were also shown small video vignettes from authentic classroom practices aimed at revealing pupils' learning difficulties when learning rational numbers and providing instructional strategies and representations to overcome these learning difficulties. In sum, the intervention and control lesson series differed both in the nature of the tasks that were used, and in the way in which these tasks were dealt with, however, with a similar instruction time. What concerns the nature of the tasks, the control lesson series included more closed instructional tasks for PSTs (e.g., see Figure 2), whereas in the intervention lesson series more open-ended instructional tasks (such as concept cartoons and video vignettes of authentic rational number lessons, e.g., see Figure 3) were used. The more open-ended and authentic instructional tasks of the intervention group, entailing various pupils' difficulties and misconceptions, were carefully chosen by the researchers and mathematics teacher trainers as a possible means to support, through metaconceptual awareness (cf. supra), PSTs' CK and PCK in the rational number domain. Besides, both lesson series differed in the way in which these tasks were enacted during the lessons. More particularly, whereas the more closed instructional tasks of the control group resulted mainly in individual and plenary activities, the video vignettes and concept cartoons of the intervention group were typically used during group discussions, complemented with plenary work. Consequently, an important role of the mathematics teacher trainer in the intervention group was to orchestrate these discussions on pupils' difficulties regarding rational numbers and different ways to remedy and overcome these difficulties. 


\section{Test instruments}

CK and PCK on rational numbers were assessed before and after the lesson series through 24 CK and 24 PCK items related to the curriculum of upper elementary school (e.g., equivalence of fractions, rational number magnitude comparison, operations with rational numbers). To maximize the content validity of the test, the test items were constructed according to the following design: the representation of the number involved (i.e., fraction or decimal number) and the nature of the mathematical knowledge (i.e., regarding the concept of rational number or regarding operations with rational numbers). In line with Shulman's (1986) conceptualization of PCK, two types of PCK items were distinguished: knowledge of pupils' misconceptions $(n=12)$ and knowledge of instructional strategies and representations $(n=12)$. The design of the test is presented in Table 2.

\section{[Table 2 near here]}

The CK and PCK tests were developed and validated in another study (Depaepe et al., 2015). To avoid retesting effects, a parallel test was developed. As illustrated in Figure 4, the parallel items covered the same mathematical content, but embedded in a similar context, or a comparable number was used without changing the complexity of the item.

\section{[Figure 4 near here]}

To control for order effects, the order of the test and parallel test was counterbalanced. The internal consistencies (Cronbach's $\alpha$ ) of the test and parallel test were respectively .66 and .67 for CK and .75 and .77 for PCK. The administration of the pretest and posttest took place in the participating teacher training institutions during class hours. Participants had 120 minutes to complete the test with a short break in between. The CK and PCK items were mixed during test administration. The time span between the pretest and the posttest was approximately two months. During this period the participants of the control and intervention group followed the 12 hours lesson series on learning to teach rational numbers in their teacher training institute.

Detailed coding guidelines were administered for scoring the items of the test. A "1" was given in case an answer was completely correct; a " 0 " in case of an incorrect answer. A " 0.5 " was only granted in case of a partially correct answer when multiple answers had to be given. The latter was the case for six of the 24 PCK items. The test was corrected by one rater. A sample of $13.55 \%$ of the tests was coded by a second independent rater. The obtained inter-rater reliability for the CK and PCK items was very high (respectively, $K=.98$ and $K=.91$ ).

\section{Analyses}

Multiple regression analyses were conducted to test whether the intervention group had better posttest scores for CK and PCK 
than the control group, after controlling for their pretest knowledge, test order, and the interaction effects of group, pretest, and test order. Regression analyses were based on standardized scores for all continuous variables (pretest CK and PCK, posttest CK and PCK); the dichotomous variables were dummy coded (group: $0=$ control; $1=$ intervention; and test order: $0=$ parallel pretest posttest; $1=$ pretest-parallel posttest). Assumptions required for regression were tested. The normal probability plot revealed that errors were normally distributed. Before presenting the results of the multiple regression analysis, we provide an overview of the descriptive results of PSTs' CK and PCK scores before and after the lesson series in both groups.

\section{Results}

\section{Descriptive results}

The mean scores (on $24^{4}$ ) and standard deviations of the CK and PCK at the pretest and posttest of the participants of the control and intervention group, and split up for the two test orders, are provided in Table 3.

\section{[Table 3 near here]}

The data revealed first, that PSTs in the control and intervention group performed almost equally well on the CK and PCK pretest. While there were no significant differences in the pretest scores between the intervention and control group, there are, in fact, pretest differences within these groups between those PST's receiving test order 0 and 1 . Therefore, we controlled in our multiple regression analyses for the interactions between group, pretest scores, and test order (cf. infra). Second, PSTs of both groups scored low on the PCK test before the lesson series, but they also had gaps in CK, especially when taking into account that the level of the CK items was based on the upper elementary school curriculum. Some illustrations of incorrect answers for different types of typically difficult PCK and CK items are provided in Figure 5.

[Figure 5 near here]

Finally, the data showed that the control group made almost no progress on CK and PCK after having followed the lesson series, whereas the intervention group showed a small increase on CK and PCK.

\footnotetext{
${ }^{4}$ The tests were scored on 24 points (1 point for each item).
} 


\section{Multiple regression}

We investigated whether there was an effect of group on the standardized posttest scores for CK and PCK (resp., zCK2 and zPCK2), when controlled for the pretest scores (resp. zCK1 and zPCK1). In order to test for interactions of intervention group, pretest scores, and test order, we set up models with the respective interaction terms ${ }^{5}$. Table 4 presents the results of the regression analyses for zCK2 and zCK2. For CK, the regression coefficients for the four interaction terms were very small $(-.10<\mathrm{B}<.02)$ and insignificant. Compared to a model without interaction terms, the change in $\mathrm{R}^{2}$ was very small $\left(\Delta \mathrm{R}^{2}<.01\right)$. For PCK, the regression coefficients for the four interaction terms were descriptively larger $(-.19<\mathrm{B}<.23)$, but also insignificant ( $\mathrm{p}>.15$ ). Compared to a model without interaction terms, the change in $\mathrm{R}^{2}$ was very small $\left(\Delta \mathrm{R}^{2}<.01\right)$. So, we concluded that interactions of intervention group, pretest scores, and test order were practically not meaningful for CK and PCK.

\section{[Table 4 near here]}

The group in which the PSTs were enrolled significantly predicted their CK scores at the posttest. Participants in the intervention group outperformed their peers of the control group by 0.59 standard deviations in CK, after controlling for prior knowledge, test order, and the interaction effects of group, pretest, and test order. Furthermore, PSTs' scores on the CK pretest significantly predicted their performances on the CK posttest. No significant effect of test order and no interaction effects were found, indicating that irrespective of test order the participants in the intervention group performed significantly better on the posttest CK than the participants of the control group. Based on these results we can confirm that the lesson series designed according to instructional design principles to promote conceptual change was more effective compared to an alternative teacher training lesson series in promoting PSTs' CK. According to Cohen (1992), the effect of group on PSTs' CK is medium.

Furthermore, the group also significantly predicted PSTs' performances on the PCK posttest. It was observed that PSTs of the intervention group outperformed PSTs of the control group by 0.38 standard deviations in PCK, after controlling for prior knowledge, test order, and the interaction effects of group, pretest, and test order. Additionally, PSTs' performance on the PCK pretest significantly predicted their performances on the posttest. Moreover, the results also indicated that there was an effect of test order, although irrespective of the test order the intervention group was outperforming the control group (i.e., no significant interaction effect of test order and group), further providing evidence for the claim that PSTs following the lesson series designed based on conceptual change theory was also more effective in enhancing their PCK compared to the lesson series in the control group. Overall, the effect size of group in terms of developing PSTs' PCK was smaller than for the development of their CK.

\footnotetext{
${ }^{5}$ (1) Group $\times$ zCK1; (2) Group $\times$ Order; (3) zCK1 $\times$ Order; (4) Group $\times$ zCK1 $\times$ Order
} 


\section{Conclusions and discussion}

Research has shown that the transition from natural to rational numbers is difficult for most elementary school pupils. One of the main sources of these difficulties is assumed to be the tendency to assign certain natural number properties to rational numbers (e.g., Vamvakoussi et al., 2012). To appropriately deal with pupils' difficulties, teachers need well-developed CK and PCK on rational numbers. Unfortunately, studies revealed serious gaps in PSTs' CK and PCK. In terms of CK they seem to suffer from misconceptions and to misapply procedures in the rational number domain. Concerning PCK, their knowledge of pupils' learning difficulties is scarce and they have only restricted knowledge of representations to prevent and/or overcome these learning difficulties. Combining elements from a design-based research approach and a more traditional teaching experiment approach a lesson series was developed on learning to teach rational numbers, informed by instructional design principles to promote conceptual change. The effectiveness of the lesson series in developing PSTs' CK and PCK on rational numbers was assessed through a comparison of the professional knowledge of PSTs in the intervention group with the professional knowledge of PSTs in the control group, following an alternative course for learning to teach rational numbers.

\section{Main conclusions}

Participants of both groups received an equally long lesson series on teaching rational numbers. Contrary to the control group, the lesson series of the intervention group was informed by research evidence on pupils' difficulties with rational numbers and on instructional strategies and representations to overcome these difficulties. More particularly, the intervention lesson series was based on principles to promote conceptual change, by (a) systematically and explicitly addressing similarities and differences between natural and rational number reasoning, (b) fostering metaconceptual awareness of existing (mis)conceptions of rational numbers (a.o. through the use of concept cartoons), and (c) providing meaningful experiences that revealed why initial conceptions are limited for working with rational numbers and why new conceptions are more intelligible, plausible, and fruitful. To realize these principles concept cartoons and video vignettes from authentic classroom situations were frequently used. Although the main focus of the lesson series was on PCK, it was also likely that it influenced PSTs' CK, especially in case of PSTs' weak CK. For instance, through being confronted with possible pupil misconceptions, it is possible that PSTs become aware of their own inadequate conceptions in the rational number domain. Participants in the intervention and control group were administered a CK and PCK pretest and posttest. The results revealed that there were no differences between PSTs' CK and PCK across both groups at the pretest, but the PSTs of the intervention group outperformed their peers of the control group on the CK and PCK posttest. Regression analyses revealed that prior knowledge (i.e., the pretest scores) significantly predicted PSTs' CK and PCK posttest scores. Furthermore, a significant effect of group was found. After controlling for prior knowledge (i.e., the pretest score), participants in the intervention group outperformed their peers of the control group for PCK, and even more for CK. Consequently, the results of our intervention study indicated that the lesson series that we developed and implemented in the intervention group was more effective in stimulating PSTs' CK and PCK than an equally long lesson series without such a focus 
on instructional design principles based on conceptual change.

\section{Theoretical value of the research findings}

First, our findings have revealed that instructional design principles to promote conceptual change, as earlier used to stimulate upper primary school pupils' science and mathematics development (e.g., Lem et al., 2017; Vamvakoussi, 2017; Vosniadou et al., 2001) are also effective in order to stimulate PSTs' CK and PCK on rational numbers. While in the earlier studies in science and mathematics education instructional techniques such as refutational texts and bridging analogies were used (e.g., Lem et al., 2017; Vamvakoussi, 2017), the present study relies on the use of concept cartoons and video vignettes to realize these instructional design principles. These techniques were particularly useful as they bring into the picture the reactions and ideas of fictitious or real learners to well-chosen rational number tasks, and encourage PSTs to reflect on these reactions in order to specifically enhance their PCK. It seems that techniques such as refutational texts and bridging analogies are more focused towards improving CK, as they do not involve the ways in which learners may think about a certain phenomenon. Our study has shown that a lesson series designed in line with instructional design principles to promote conceptual change is more effective than an alternative lesson series in which this explicit focus is absent, irrespective of PSTs' prior knowledge and without increasing the instruction time. On the one hand, the present study significantly contributes to the existing research literature, as studies focusing on the effects of systematically designed interventions on the development of teachers' professional knowledge are scarce (Evens, Elen, \& Depaepe, 2015). On the other hand, the designed instructional activities and the techniques that were implemented to elicit conceptual change can function as a frame of reference for researchers to design lesson series to foster PSTs' professional knowledge growth in other domains.

Second, our study shows that our intervention is in particular successful in developing PSTs' CK, although it mainly focuses on PCK. This finding might suggest that a thorough change in PSTs' PCK should be preceded by a change in CK. This observation might provide further evidence for the close association between the constructs of CK and PCK (e.g., Baumert et al. ,2010; Depaepe et al., 2015; Kleickmann et al., 2015). Moreover, a similarly positive effect of a PCK course on participants' CK was observed by Smith and Neale (1989) for in-service teachers in the domain of science. Their course offered opportunities to implement conceptual change instructional strategies and, thus, focused mainly on PCK. However, the program had only a marginal effect on PCK development, whereas CK development was much higher. According to van Driel, Verloop, and de Vos (1998) "this is explained by the fact that participants were still constructing a "deeply principled conceptual knowledge of the content" (Smith \& Neale, 1989, p. 17), the latter apparently being perceived as a prerequisite for the development of PCK" (p. 680). In future research it is important to disentangle the separate impact of CK and PCK courses on teachers' CK and PCK development (see, e.g., Kleickmann et al., 2017). 


\section{Practical value of the research findings}

A first practical value of the findings is that it provides concrete suggestions and materials (Van Roy et al., 2014) to other teacher educators on how to design courses in teacher training, even beyond the domain of rational numbers. The present study has revealed that this material can improve PSTs' CK and PCK on rational numbers. In the longer run, being equipped with better CK and PCK can impact teachers' instructional quality and hence, pupils' learning outcomes, as research has convincingly shown the association between teachers' professional knowledge and their instructional quality (e.g., Baumert et al., 2010; Kunter et al., 2013).

Second, the present study was practically relevant for the mathematics teacher trainers involved in this study. Being involved in the co-development of the lesson series has been a professional training experience for the mathematics teacher trainers themselves. In this sense, Gravemeijer and van Eerde (2009) use the notion "dual design research" to refer to the fact that the teacher (in this study: the teacher trainers) experiences a learning process through the co-design of the intervention lesson series, parallel to the learning process of the learners (in this study: PSTs) as a result of being enrolled in the design experiment.

\section{Limitations and future directions}

The present was conducted in an authentic context with a high involvement of mathematics teacher trainers, and in the design and implementation of the teaching materials. However, the high ecological validity of this study is associated with, also some drawback for its internal validity. A first drawback is the non-experimental nature of the study as we worked with existing groups of PSTs and these groups were non-randomly assigned to the control or the intervention group. Although participants were not randomly assigned to either the intervention or the control group, we tried to establish baseline equivalence between the two groups by taking existing classes of PSTs in the control and intervention group from the same three teacher training institutes, albeit in two different cohorts. As the CK and PCK pretests, as well as the background characteristics (gender, age) of the control and intervention group did not significantly differ, it seems that both groups are comparable. A second drawback of the high ecological validity of the study is that other unknown variables might have impacted participants' performances on the CK and PCK test. A third drawback of the present study is that the lesson series of the intervention group differed from the lesson series of the control group in several respects. The design of our study does not enable us to distil which features of the lesson series that contributed most to PSTs' growth in CK and PCK. Despite these drawbacks, we aimed to foster internal validity in this study by explicitly combining principles of design experiments with principles of more traditional teaching experiments (e.g., pretestposttest design with experimental and control group, and controlling for possible confounding variables such as age, gender, and prior knowledge). 
Further experimental research may be appropriate to systematically investigate the isolated impact of different features of the lesson series on professional knowledge development. For instance, it might be worthwhile to design and evaluate interventions that differ from each other in only one aspect, such as in explicitly describing similarities and differences between natural and rational numbers, or in reflecting on and discussing concept cartoons. Iterations of interventions that differ from each other on only one feature would provide systematic evidence on how concretely PSTs' professional knowledge develops for each design principle and in what specific aspects (e.g., regarding the distinct subcomponents of PCK) the intervention is successful or not successful. Such research would provide more information on which combination of design principles is most successful to develop PSTs' professional knowledge. Moreover, further research might investigate how the instructional activities and the way they were enacted in the experimental lesson series can be further elaborated and refined in order to further improve the professional growth of PSTs in the domain of rational numbers. This might be especially important as our findings have revealed that for $\mathrm{CK}$ - and even more for PCK - there is further room for improvement.

Nevertheless, developing programs that enhance PSTs' CK and PCK represents an important goal of initial teacher education. Our study demonstrated that a research-informed lesson series focusing on knowledge of pupils' misconceptions and representations to overcome these misconceptions was successful in enhancing that knowledge, without enlarging the instruction time in teacher training.

\section{References}

Akamca, G. Ö., Ellez, A. M., \& Hamurcu, H. (2009). Effects of computer aided concept cartoons on learning outcomes. ProcediaSocial and Behavioral Sciences, 1, 296-301.

Ball, D. L. (1990). The mathematical understandings that prospective teachers bring to teacher education. The Elementary School Journal, 90, 449-466. doi: 10.1086/461626

Ball, D. L., Thames, M. H., \& Phelps, G. (2008). Content knowledge for teaching: What makes it special? Journal of Teacher Education, 59, 389-407. doi: 10.1177/0022487108324554

Baumert, J., Kunter, M., Blum, W., Brunner, M., Voss, T., Jordan, A., et al. (2010). Teachers' mathematical knowledge, cognitive activation in the classroom, and student progress. American Educational Research Journal, 47, 133-180. doi:

$10.3102 / 0002831209345157$ 
Beckmann, S. (2005). Mathematics for elementary school teachers and activities. Boston: Pearson - Addison Wesley.

Behr, M. J., Lesh, R., Post, T. R., \& Silver, E. (1983). Rational number concepts. In R. Lesh \& M. Landau (Eds.), Acquisition of mathematical concepts and processes (pp. 92-127). New York: Academic Press.

Blömeke, S., Felbrich, A., Müller, C., Kaiser, G., \& Lehmann, R. (2008). Effectiveness of teacher education. ZDM - The International Journal on Mathematics Education, 40, 719-734. doi: 10.1007/s11858-008-0096-x

Charalambous, C. Y., \& Pitta-Pantazi, D. (2007). Drawing on a theoretical model to study students' understandings of fractions. Educational Studies in Mathematics, 64, 293-316. doi:10.1007/s10649-006-9036-2

Cohen, J. (1992). A power primer. Psychological Bulletin, 112, 155-159. doi :10.1037/0033-2909.112.1.155

Cramer, K. A., Post, T.R., \& delMas, R.C. (2002). Initial fraction learning by fourth- and fifth-grade students: A comparison of the effects of using commercial curricula with the effects of using the rational number project curriculum. Journal for Research in Mathematics Education, 33, 111-144. doi:10.2307/749646

De Bock, D., Janssens, D., \& Deprez, J. (2016). The enrichment of Belgian secondary school mathematics with elements of the Dutch model of Realistic Mathematics Education since the 1980s. In M. Van den Heuvel-Panuizen (Ed.), Reflections from abroad on the Netherlands didactic tradition in mathematics education (p. 13). Dordrecht-Heideblerg-New York: Springer.

De Bock, D., Van Dooren, W., \& Verschaffel, L. (2016). Searching for alternatives for New Math in Belgian primary schools: Influence of the Dutch model of Realistic Mathematics Education. In M. Van den Heuvel-Panuizen (Ed.), Reflections from abroad on the Netherlands didactic tradition in mathematics education (p. 5). Dordrecht-Heidelberg-New York: Springer.

Depaepe, F., Torbeyns, J., Vermeersch, N., Janssens, D., Janssen, R., Kelchtermans, G., Verschaffel, L., \& Van Dooren, W. (2015). Teachers' content and pedagogical content knowledge on rational numbers: A comparison of prospective elementary and lower secondary school teachers. Teaching and Teacher Education, 47, 82-92. doi: 10.1016/j.tate.2014.12.009

Driel, van, J. H., Verloop, N., de Vos, W. (1998). Developing science teachers' pedagogical content knowledge. Journal of Research in Science Teaching, 35, 673-695. Doi: 10.1002/(SICI)1998-2736(199808) 
Evens, M., Elen, J., \& Depaepe, F. (2015). Developing pedagogical content knowledge: Lessons learned from intervention studies. Educational Research International, Article ID 790417, 23 pages. doi: 10.1155/2015/790417

Evens, M., Larmuseau, C., Dewaele, K., Van Craesbeek, L., Elen, J., \& Depaepe, F. (2017). The effects of a systematically designed online learning environment on preservice teachers' professional knowledge. Journal of Digital Learning in Teacher Education, 33, 103-113. doi: 10.1080/21532974.2017.1314779

Gravemeijer, K., \& Cobb, P. (2006). Design research from the learning design perspective. In J. van den Akker, K. Gravemeijer, S. McKenney, \& N. Nieveen (Eds.), Educational design research (pp. 45-85). London: Routledge.

Gravemeijer, K., \& Van Eerde, D. (2009). Design research as a means for building a knowledge base for teachers and teaching in mathematics education. Elementary School Journal, 109, 510-524.

Grossman, P. L. (1989). A study in contrast: Sources of pedagogical content knowledge for secondary English. Journal of Teacher Education, 40, 24-31. doi: 10.1177/002248718904000504

Hartnett, P., \& Gelman, R. (1998). Early understanding of numbers: Paths or barriers to the construction of new understanding? Learning and Instruction, 8, 341-374. doi:10.1016/S0959-4752(97)00026-1

Hattie, J., Biggs, J., \& Purdie, N. (1996). Effects of learning skills interventions on student learning: A meta-analysis. Review of Educational Research, 66, 99-136. doi: 10.3102/00346543066002099

Keogh, B., \& Naylor, S. (1999). Concept cartoons, teaching and learning in science: An evaluation. International Journal of Science Education, 21, 431-446. doi: 10.1080/095006999290642

Khashan, K. H. (2014). Conceptual and procedural knowledge of rational numbers for Riyadh elementary school teachers. Journal of Education and Human Development, 3(4), 181-197. doi: 10.15640/jehd.v3n4a17

Kleickmann, T., Richter, D., Kunter, M., Elsner, J., Besser, M., Krauss, S., Cheo, M., \& Baumert, J. (2015). Content knowledge and pedagogical content knowledge in Taiwanese and German mathematics teachers. Teaching and Teacher Education, 46, 115126. doi:10.1016/j.tate.2014.11.004 
Kleickmann, T., Tröbst, S., Heinze, A., Bernholt, A., Rink, R, \& Kunter, M. (2017). Teacher knowledge experiment: Conditions of the development of pedagogical content knowledge. In D. Leutner, J. Fleischer, J. Grünkorn, \& E. Klieme (Eds.), Competence assessment in education. Methodology of educational measurement and assessment (pp. 111-129). Dordrecht-Heidelberg-New York: Springer. doi: 10.1007/978-3-319-50030-0_8

Kunter, M., Klusmann, U., Baumert, J., Richter, D., Voss, T., \& Hachfeld, A. (2013). Professional competence of teachers: Effects on instructional quality and student development. Journal of Educational Psychology, 105, 805-820. doi:10.1037/a0032583

Lamon, S. J. (2005). Teaching fractions and ratios for understanding: Essential content knowledge and instructional strategies for teachers (2nd Ed.). Mahwah: Lawrence Erlbaum Associates.

Lem, S., Onghena, P., Verschaffel, L., \& Van Dooren, W. (2017). Using refutational text in mathematics education. ZDM, 49, 509-518. doi:10.1007/s11858-017-0843-y

Lim-Teo, S. K., Chua, K. G., Cheang, W. K., \& Yeo, J. K. (2007). The development of diploma in education student teachers' mathematics pedagogical content knowledge. International Journal of Science and Mathematics Education, 5, $237-261$. doi:10.1007/s10763-006-9056-5

Moss, J., \& Case, R. (1999). Developing children's understanding of the rational numbers: A new model and an experimental curriculum. Journal for Research in Mathematics Education, 30, 122-147. doi:10.2307/749607

Newton, K. (2008). An extensive analysis of preservice elementary teachers' knowledge of fractions. American Educational Research Journal, 45, 1080-1110. doi: 10.3102/0002831208320851

Ni, Y., \& Zhou, Y. D. (2005). Teaching and learning fraction and rational numbers: The origins and implications of whole number bias. Educational Psychologist, 40, 27-52. doi: 10.1207/s15326985ep4001_3

Piaget, J. (1971). Science of education and the psychology of the child. London: Longmain. 
Qian, H., \& Youngs, P. (2016). The effect of teacher education programs on future elementary mathematics teachers' knowledge: A five-country analysis using TEDS- M Data. Journal of Mathematics Teacher Education 19, 371-396. doi:10.1007/s10857-014-9297-0.

Sheffield, L. J., \& Cruikshank, D. E. (2000). Teaching and learning elementary and middle school mathematics (4 ${ }^{\text {th }}$ Edition). New York: John Wiley \& Sons, Inc.

Shulman, L. S. (1986). Those who understand: Knowledge growth in teaching. Educational Researcher, 15(2), 4-14. doi: $10.3102 / 0013189 X 015002004$

Siegler, R. S., Duncan, G. J., Davis-Kean, P. E., Duckworth, K., Claessens, A., Engel, M., et al. (2012). Early predictors of high school mathematics achievement. Psychological Science, 23, 691-697. doi: 10.1177/0956797612440101

Smith, D. C., \& Neale, D. C. (1989). The construction of subject matter knowledge in primary science teaching. Teaching and Teacher Education, 5, 1-20. doi: 10.1016/0742-051x(89)90015-2

Swalm, M. (2014). Design research in mathematics education. In S. Lerman (Ed.), Encyclopedia of mathematics education (pp. 148-152). Dordrecht-Heidelberg-New York: Springer. doi: 10.1007/978-94-007-4978-8

Tirosh, D. (2000). Enhancing prospective teachers' knowledge of children's conceptions: The case of division of fractions. Journal for Research in Mathematics Education, 31, 5-25. doi:10.2307/749817

Turnuklu, E. B., \& Yesildere, S. (2007). The pedagogical content knowledge in mathematics: Pre-service primary mathematics teachers' perspectives in Turkey. Issues in the Undergraduate Mathematics Preparation of School Teachers, 1, 1-13.

Vanassche, E., \& Kelchtermans, G. (2016). Facilitating self-study of teacher education practices: toward a pedagogy of teacher educator professional development. Professional Development in Education, 42, 100-122.

Van Roy, P., Hawrijk, I., Vermeersch, N., Palmaerts, A., \& Depaepe, F. (2014). Breuken, kommagetallen en procenten. Een didactiek voor het basisonderwijs. [Fractions, decimal numbers, and percentages. An instructional approach for elementary school] Leuven: Acco Uitgeverij. 
Vamvakoussi, X. (2017). Using analogies to facilitate conceptual change in mathematics learning. ZDM, 49, $497-507$. doi:10.1007/s11858-017-0857-5

Vamvakoussi, X., Van Dooren, W., \& Verschaffel, L. (2012). Naturally biased? In search for reaction time evidence for a natural number bias in adults. The Journal of Mathematical Behavior, 31, 344-355. doi:10.1016/j.jmathb.2012.02.001

Vamvakoussi X., Vosniadou S., \& Van Dooren W. (2013). The framework theory approach applied to mathematics learning. In S. Vosniadou (Ed.), International handbook of research on conceptual change (pp. 305-321). New York: Routledge.

Verburgh, A., Schouteden, W., \& Elen, J. (2013). Patterns in the prevalence of research-related goals in higher education programmes. Teaching and Teacher Education, 18, 298-310. doi: 10.1080/13562517.2012.719153

Vamvakoussi, X., \& Vosniadou, S. (2012). Bridging the gap between the dense and the discrete: The number line and the "rubber line” bridging analogy. Mathematical Thinking and Learning, 14, 265-284 http://dx.doi.org/10.1080/10986065.2012.717378

Vosniadou, S., Ioannides, C., Dimitrakopoulou, A., \& Papademetriou, E. (2001). Designing learning environments to promote conceptual change in science. Learning and Instruction, 11, 381-419. doi: 10.1016/s0959-4752(00)00038-4

Vosniadou, S., \& Verschaffel, L. (2004). Extending the conceptual change approach to mathematics learning and teaching. Learning and Instruction, 14, 445-451. doi:10.1016/j.learninstruc.2004.06.014

Whitacre, I., \& Nickerson, S. D. (2016). Investigating the improvement of prospective elementary teachers' number sense in reasoning about fraction magnitude. Journal of Mathematics Teacher Education, 19, 57-77. doi:10.1007/s10857-014-9295-2 